\title{
Layered chromitite: a signpost towards a hydrated magma chamber in the Archean
}

\author{
K. SAJEeV ${ }^{1, *}$, S. Veni ${ }^{1}$, B.F. WindLeY ${ }^{2}$ \\ ${ }^{1}$ Centre for Earth Sciences, Indian Institute of Science, \\ Bangalore, India, sajeev@iisc.ac.in \\ ${ }^{2}$ Department of Geology, The University of Leicester, \\ Leicester, UK
}

Theoretical, seismological and experimental studies have demonstrated that hydrous supracrustal and arc materials are transported to mantle depths in subduction channels. However, such processes in the Archean eon are not well documented. It is still a topic of debate whether or to what extent the magma chambers and the mantle of the early Earth were hydrous. Chromite, a major cumulate phase in maficultramafic magmas, commonly associated with olivine, is a good petrogenetic indicator, and provides critical information on the characteristics and genesis of its source. Overgrowths of metamorphic chromite, also common in many ancient layered complexes, are invariably associated with olivine or hydrated serpentine. Here we report a natural occurrence of magmatic chromite in total absence of olivine from the similar Archaean layered complexes of Sittampundi (eclogite facies, southern India) and Fiskenæsset (granulite facies, western Greenland). This observation provides critical information on magma chambers from hydrous island arcs, indicating deep subduction of hydrous material and mixing of $\mathrm{H}_{2} \mathrm{O}$ with the mantle in the Meso-Neoarchean. Our results suggest that the composition of a subducted hydrous primary magma inhibits the formation of olivine and instead produces an unusual $\mathrm{Cr}$-spinel-Cr-amphibole-Cr-corundum association in a narrow region for amphibole-present and chlorite-absent conditions in the upper mantle to lower crust. The hydration of the mantle was well advanced by the mid-late Archaean. 